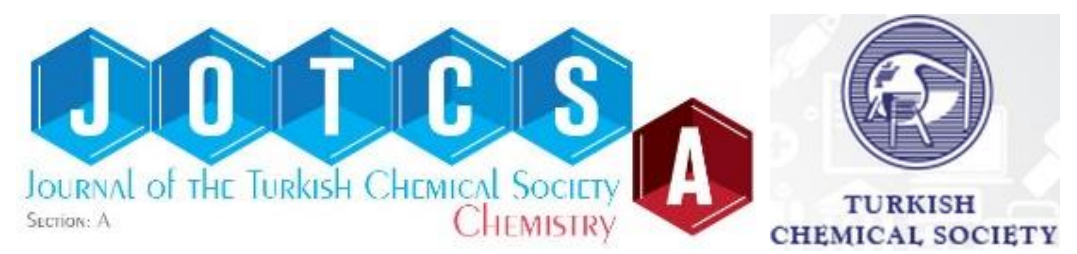

\title{
Synthesis and Characterization of Novel Pd and Cu vic-dioxime Precursors for Their Supercritical Deposition on Multiwalled Carbon Nanotubes
}

\author{
Fatma Ulusal ${ }^{1} *$, Bilgehan Güzel ${ }^{1}$ \\ ${ }^{1}$ Chemistry Department, Art and Science Faculty, University of Çukurova, 01330, Adana, \\ Turkey
}

\begin{abstract}
Novel precursors were developed for deposition of $\mathrm{Cu}$ and $\mathrm{Pd}$ nanoparticles on multiwalled carbon nanotubes for supercritical carbon dioxide deposition technique. 3(heptadecafluorooctyl)aniline-vic-dioxime and phenanthrenequinone dioxime were used as ligands in synthesis of the palladium and copper precursors. All synthesized ligands and complexes were characterized with elemental analysis, ${ }^{1} \mathrm{H}$ and ${ }^{19} \mathrm{~F}$ NMR, FT-IR and magnetic susceptibility technique. Deposition of these precursors in supercritical carbon dioxide was performed at $363 \mathrm{~K}$ in the pressure $0.69 \mathrm{MPa} \mathrm{H}$ and $27.6 \mathrm{MPa} \mathrm{CO}_{2}$. Surface morphology of metal deposited multiwalled carbon nanotubes has been investigated with X-ray diffraction, highresolution transmission electron microscopy and scanning electron microscopy with EDX. TEM micrographs showed homogenous distributions of $\mathrm{Cu}$ and $\mathrm{Pd}$ nanoparticles on the multiwalled carbon nanotubes. The nature and crystallinity of the nanoparticles were confirmed using XRD. This study showed that these novel vic-dioxime complexes are suitable precursors for the preparation of supported metal nanoparticles in supercritical carbon dioxide.
\end{abstract}

Keywords: Vic-dioxime, precursor, multi-walled carbon nanotubes, supercritical deposition.

Submitted: December 12, 2017. Accepted: March 29, 2018.

Cite this: Ulusal F, Güzel B. Synthesis and Characterization of Novel Pd and Cu vic-dioxime Precursors for Their Supercritical Deposition on Multiwalled Carbon Nanotubes. JOTCSA. $2018 ; 5(2): 635-52$.

DOI: http://dx.doi.org/10.18596/jotcsa.363662.

*Corresponding author. E-mail: fatma ulusal@hotmail.com, GSM: (0539)886 8110. 


\section{INTRODUCTION}

The green chemistry techniques gain importance day by day due to their use as an alternative solvent. Especially, supercritical fluids (SCF) have been used in various techniques such as organic synthesis, extraction, cosmetics, energy, food, materials, pharmaceutics, chemistry, sterilization, formulation, impregnation, cleaning, waste treatment and deposition of metals on the solid materials $(1,2)$. For the past two decades, the deposition process in the $\mathrm{scCO}_{2}$ environment has become a focus of interest for scientists and has made an important contribution to the preparation of catalysts, especially with green chemistry. The method of preparing these nano-catalysts in supercritical fluids (SCF) follows a three-step deposition process. The first step involves dissolving a metallic precursor and treating the support material in the SCF. In the second step, the precursor is adsorbed onto the support surface. The last step requires the thermal or chemical reduction of the precursors to their metallic form.

The deposition of transition metals such as $\mathrm{Ni}, \mathrm{Pd}, \mathrm{Cu}, \mathrm{Pt}$, and $\mathrm{Rh}$ on a solid support is an important research area because of the extensive applications of these supported nanoparticles in a wide variety of disciplines (3-6). Metal nanoparticles on supporting materials are commonly used as catalysts for hydrogenation, oxidation, synthesis, Heck and Suzuki-Miyaura C-C bond forming reactions. (5-8). Among various supports, carbon materials are desired for a wide variety of applications (9). Common substrates used as supports in deposition are carbon black, activated carbon, carbon aerogel and carbon nanotubes (CNTs). Carbon-supported nanoparticle metals are used widely as catalysts for a variety of reactions; palladium catalysts deposited on multi-walled carbon nanotubes (MWCNTs) are often used in hydrogenation and oxidation reactions (10). This catalyst also shows a high electro-catalytic activity in oxygen reduction for potential fuel cell application $(11,12)$.

The metal precursor plays an important role in the control of the morphology of the metal nanoparticles (8). The metallic precursors used so far include complexes containing cyclooctadiene, dithiocarbamate, hexamethylene glycol dimethyl ether, hexamethyl triethylene, acetylacetonate, and tetramethyl heptanedionate ligands (13-18). However, these precursors have proven to be inadequate for some metals due to the formation of large clusters on the surface as well as the wide size distribution of the nanoparticles (18). By synthesizing new precursors, it is expected that better alternatives allowing for adequately small sizes and uniform distribution of nickel nanoparticles on the substrate will be discovered. An oxime is defined as a compound with a $\mathrm{C}=\mathrm{N}-\mathrm{OH}$ functional group; a molecule with two of these functional groups on adjacent carbons is known as a vic-dioxime. Another advantage of vic-dioxime type precursors is their inexpensive and easy synthesis with a wide variety of metals, such as $\mathrm{Ni}, \mathrm{Pd}, \mathrm{Cu}, \mathrm{Co}$, and Fe $(17,19)$. 
Our group has been working on developing new precursors used in the $\mathrm{scCO}_{2}$ deposition due to the limited alternatives in the literature. So far, we have been able to synthesize $\mathrm{Pd}(\mathrm{II})$ complexes of phenanthrenequinone dioxime and dimethylglyoxime ligands and carried out depositions on alumina in the $\mathrm{SCCO}_{2}$ medium and used the nanocatalysts for Suzuki-Miyaura coupling reactions (1). In addition to this, we also synthesized bipyridyl-derived $\mathrm{Pd}(\mathrm{II})$ complexes and deposited Pd on SBA-15 supports in the $\mathrm{SCCO}_{2}$ medium (20). In this paper, 3(heptadecafluorooctyl)aniline-vic-dioxime and phenanthrene quinonedioxime were synthesized, used as a ligands for preparing $\mathrm{Cu}$ and Pd precursors. The preparation of the M/MWCNT composites was done by adsorbing the dissolved precursors in $\mathrm{scCO}_{2}$ followed by a subsequent chemical reduction by introduction of a mixture of $\mathrm{H}_{2}$ and $\mathrm{CO}_{2}$ gas into the system to produce the metal nanoparticles. The resulting MWCNT supported metal nanocatalysts were characterized with XRD, HR-TEM and TEM. A comparative analysis of their solubility in supercritical carbon dioxide, the size and distribution of the resulting nanoparticles is reported.

\section{MATERIALS AND METHODS}

All chemicals were obtained from Sigma Aldrich and used without further purification. It was characterized by general spectroscopic techniques. Multiwalled carbon nanotubes (MWCNT), obtained from Sigma Aldrich, were used and had the following average dimensions: O.D. xL (6$9 \mathrm{~nm} \times 5 \mu \mathrm{m}$ ), diameter (mode, $5.5 \mathrm{~nm}$; median, $6.6 \mathrm{~nm}$ ). Elemental analysis was performed with Thermo Scientific Flash $2000 \mathrm{CHN}$. The ${ }^{1} \mathrm{H}$ NMR spectra of ligands were recorded on a Bruker AVANCE- 500 (in DMSO). The FT-IR spectra of compounds were obtained on a Thermo FT-IR spectrometer; Smart ITR diamond attenuated total reflection (ATR). The magnetic susceptibilities of metal complexes were determined on a Sherwood Scientific Magnetic Susceptibility balance (Model $\mathrm{MK} 1$ ) using $\mathrm{CuSO}_{4} .5 \mathrm{H}_{2} \mathrm{O}$ as a calibration standard at room temperature; diamagnetic corrections were calculated from Pascal's constants. The separation and washing of the MWCNTs by precipitation were performed with a Serico 80-2 centrifuge machine. The XRD spectra were recorded on Rigaku Miniflex CuKa, $\lambda=0.154 \mathrm{~nm}$. High-resolution transmission electron microscope (HR-TEM) and hgh-angle annular dark-field scanning TEM (HAADF-TEM) were recorded on Jem Jeol 2100F 200kV HR-TEM. Scanning Electron Microscopy (SEM) images were recorded on Zeiss Supra 55. The resolution of this microscope is a working distance of $10 \mathrm{~mm}$ at an accelerating voltage of $10 \mathrm{kV}$. The metal/MWCNTs nanoparticles were mounted on platinum pins with double-sided carbon tape and their corresponding SEM images were recorded. Elemental analysis of metals was obtained from EDAX Genesis EDS system. We described the effect of a dioxime derivative on Pd loading yield by inductively coupled plasmaoptical emission spectrometry (ICP-OES) (Perkin Elmer 2100 DV).

Synthesis of phenanthrenequinone dioxime [PTQD]: PTQD was synthesized to be used as ligand according to the methodology given in (21). A nitrogen-flushed mixture of 9,10phenanthrenequinone $(2.1331 \mathrm{~g}, 10.2 \mathrm{mmol})$, hydroxylamine hydrochloride $(2.7 \mathrm{~g}, 35.6 \mathrm{mmol})$, 
and $\mathrm{BaCO}_{3}(2.91 \mathrm{~g}, 15.3 \mathrm{mmol})$ in $150 \mathrm{~mL}$ of anhydrous ethanol was refluxed for 24 hours. Then, the mixture was cooled to room temperature, after which the ethanol was evaporated using a rotary evaporator. The residue was treated with $250 \mathrm{~mL}$ of $0.25 \mathrm{M} \mathrm{HCl}$. This mixture was stirred for 1.5 hours and filtered. The filtered solid was washed with water, ethanol, and anhydrous diethyl ether respectively; then, it was dried in a vacuum desiccator to afford $2.4 \mathrm{~g}$ (98\%) of phenanthrenequinone dioxime as a yellowish solid: m.p.: $214.2{ }^{\circ} \mathrm{C}$; Elemental analysis for $\left[\mathrm{C}_{14} \mathrm{H}_{10} \mathrm{O}_{2} \mathrm{~N}_{2}\right]$, calculated: $\mathrm{C}, 70.58 ; \mathrm{N}, 11.76 ; \mathrm{H}, 4.23$, found: $\mathrm{C}, 68.92 ; \mathrm{N}, 11.30 ; \mathrm{H}, 4.14 ;$ IR $3140 \mathrm{~cm}^{-1}(\mathrm{O}-\mathrm{H}), 3029 \mathrm{~cm}^{-1}(\mathrm{C}-\mathrm{H} \mathrm{Ph}), 1647 \mathrm{~cm}^{-1}(\mathrm{C}=\mathrm{N}), 1598 \mathrm{~cm}^{-1}(\mathrm{C}=\mathrm{C} \mathrm{Ph}), 1297-1341 \mathrm{~cm}^{-1}$ $(\mathrm{N}-\mathrm{O}), 910-1021 \mathrm{~cm}^{-1}(\mathrm{~N}-\mathrm{O}) ;{ }^{1} \mathrm{H} \mathrm{NMR}\left(\mathrm{CDCl}_{3}\right), \delta \mathrm{ppm}: 12.45-12.10(\mathrm{~m}, 2 \mathrm{H},-\mathrm{OH}), 8.4-7.4(\mathrm{~m}$, $4 \mathrm{H}, \mathrm{Ph})$. The ligand was found to be soluble in some organic solvents like THF, DMSO, ethanol and acetone; and insoluble in chloroform, n-hexane and water. (Figure 1.)

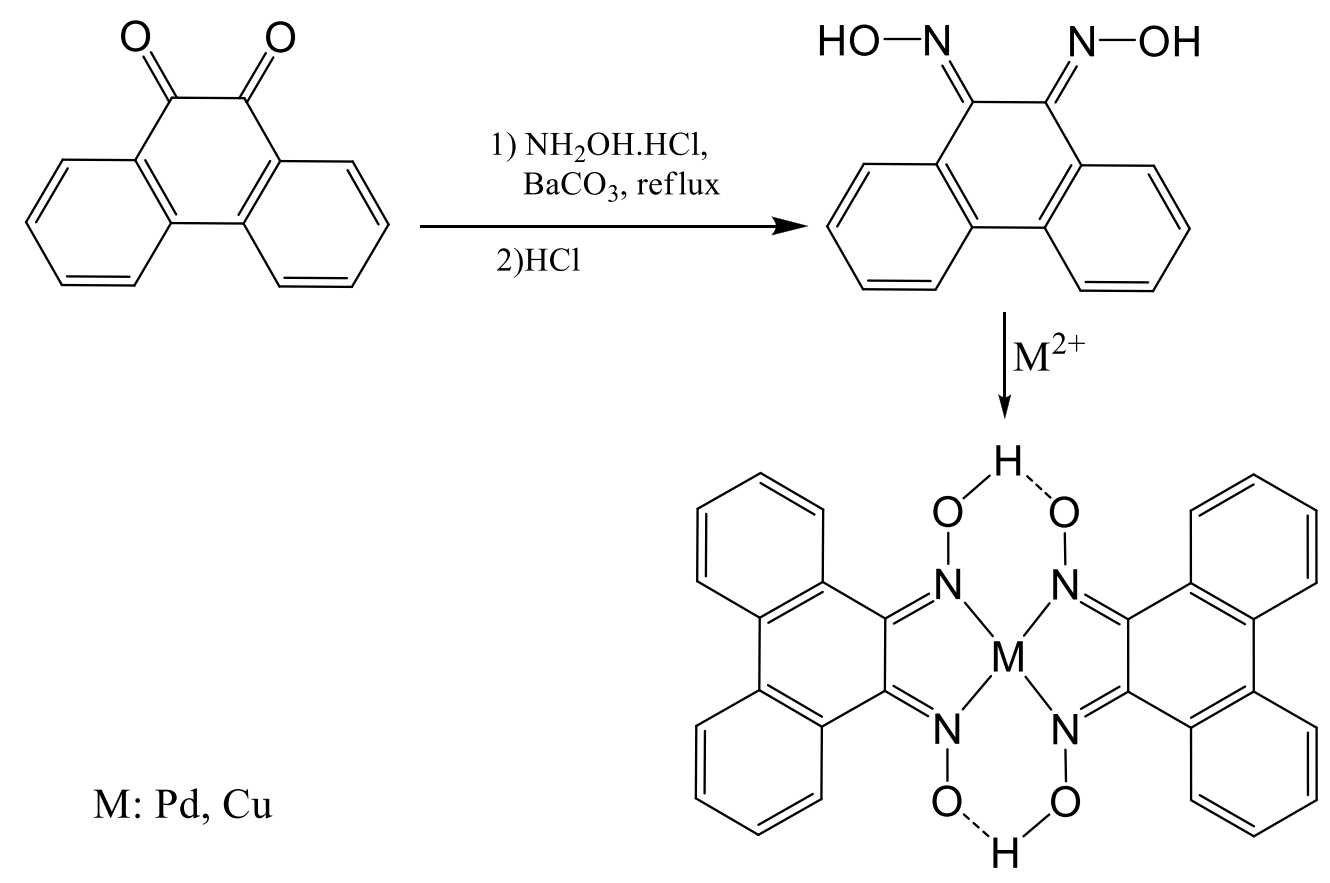

Figure 1. Synthesis of phenanthrenequinone dioxime and metal complexes.

Synthesis of 3-perfluoro-vic-dioxime [3PFVD]: The ligand was synthesized to be used as ligand according to the methodology given in (19). A solution of 3-(heptadecafluorooctyl) aniline $(1 \mathrm{mmol})$ in $20 \mathrm{~mL}$ of absolute ethanol at $-10{ }^{\circ} \mathrm{C}$ was added to a solution of antimonochloroglyoxime $(1 \mathrm{mmol})$ in $10 \mathrm{~mL}$ of ethanol at $-10{ }^{\circ} \mathrm{C}(22,23)$. Then the mixture was stirred for 4.5 hours, keeping its temperature under $-10^{\circ} \mathrm{C}$. When the solution turned yellow, the $\mathrm{pH}$ was brought to 6 by adding $0.1 \mathrm{M} \mathrm{NaOH}$, in a drop wise manner. As a result, its color turned to yellowish-orange. $30 \mathrm{~mL}$ of water was added to the mixture and left for 20 days. After this time, yellow crystals formed. These were filtered and then dried in a vacuum desiccator. Yield: \%66. m.p.: $205.32{ }^{\circ} \mathrm{C}$. Elemental analysis $\left[\mathrm{C}_{16} \mathrm{H}_{8} \mathrm{~F}_{17} \mathrm{~N}_{3} \mathrm{O}_{2}\right]$; Found $\mathrm{C}, 32.28 ; \mathrm{H}, 1.07 ; \mathrm{N}$, $6.20 \%$, calculated C, 32.18; H, 1.35; N, 7.04\%; FT-IR (ATR, mmax/ $\left.\mathrm{cm}^{-1}\right) ; 3383(\mathrm{~N}-\mathrm{H}), 3244$ $(\mathrm{O}-\mathrm{H}), 1611(\mathrm{C}=\mathrm{N}), 1608-1527(\mathrm{C}=\mathrm{C}), 1310(\mathrm{~N}-\mathrm{O}), 1202(\mathrm{C}-\mathrm{F}), 950(\mathrm{~N}-\mathrm{O}) ;{ }^{1} \mathrm{H}$ NMR $\left(\mathrm{CDCl}_{3}\right), \delta$ 
ppm: $11.5(\mathrm{~d}, 2 \mathrm{H},-\mathrm{OH}), 8.0(\mathrm{~s}, 1 \mathrm{H},-\mathrm{NH}), 7.26-6.8(\mathrm{~m}, 4 \mathrm{H}, \mathrm{Ph}), 3.8(\mathrm{~s}, 1 \mathrm{H},=\mathrm{CH}) ;{ }^{19} \mathrm{~F} \mathrm{NMR}$ $\left(\mathrm{CDCl}_{3}\right)$, $\delta \mathrm{ppm}:-80.73,-80.75,-80.77,-80.81\left(\mathrm{CF}_{2} \mathrm{CF}_{3}\right),-110.92,-110.85,-110.78,-121$, $122,-123\left(\mathrm{CF}_{2}-\mathrm{CF}_{2}-\mathrm{CF}_{2}\right)$. The yellowish-orange ligand proved soluble in some organic solvents like THF, DMSO, ethanol and acetone; and insoluble in chloroform, n-hexane and water. (Figure 2.).

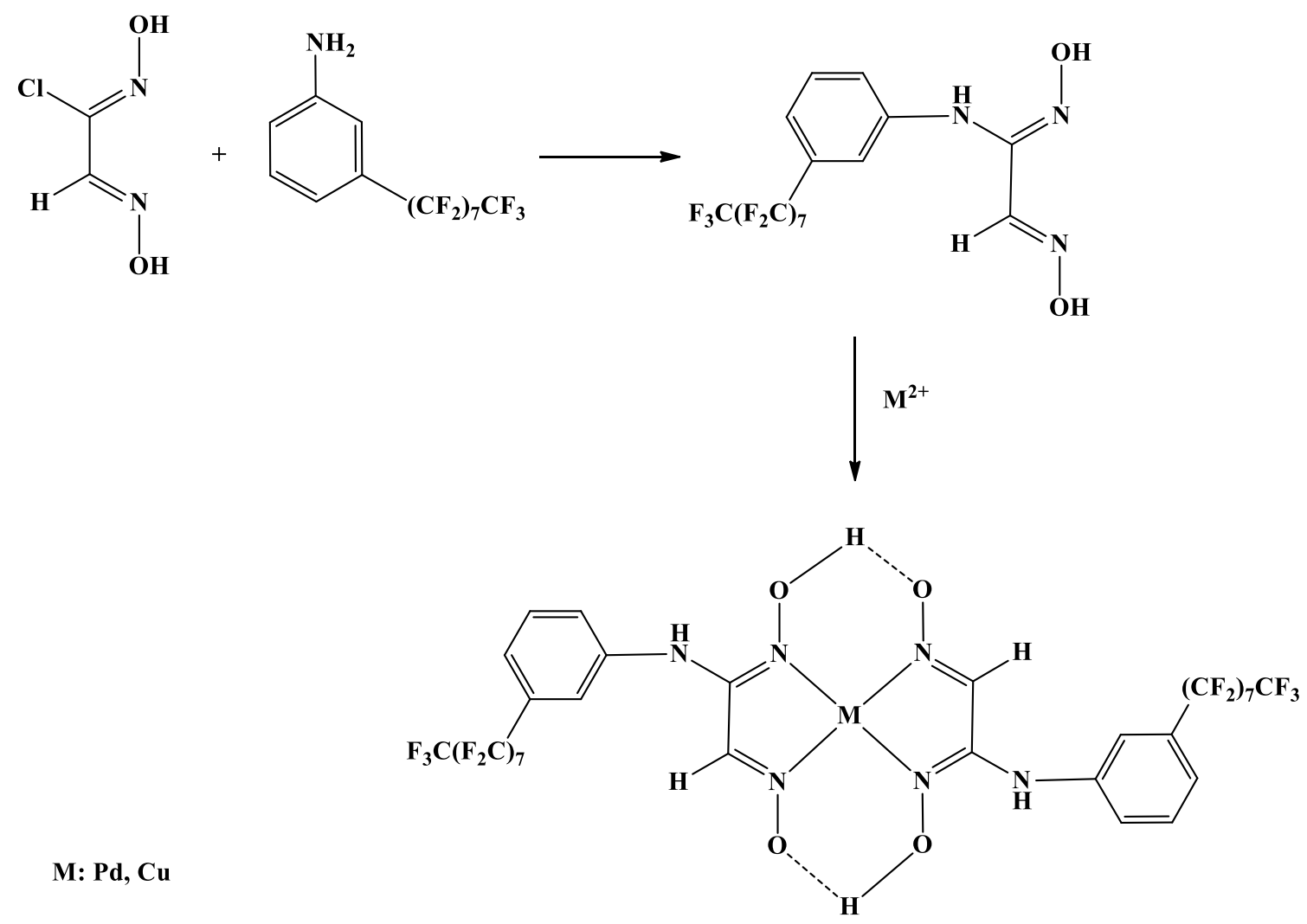

Figure 2. Reaction of $3 P F V D$ and its metal complexes.

Synthesis of bis(3-perfluoro-vic-dioxime)copper(II) [Cu(3PFVD)2]: The complex was synthesized to be used as metaloorganic precursor according to the methodology given in (19). A solution of vic-dioxime ( $2 \mathrm{mmol}$ ) in $15 \mathrm{~mL}$ of absolute ethanol was added to a solution of copper(II) acetate monohydrate ( $1 \mathrm{mmol}$ ) in $10 \mathrm{~mL}$ of absolute ethanol. The mixture was refluxed at $65^{\circ} \mathrm{C}$ for 4.5 hours and then it was allowed to cool to room temperature. The precipitate was filtered and dried in desiccator by vacuum to furnish the pure $\mathrm{Cu}$ oxime. Yield: $80 \%$ m.p. $>330$ ${ }^{\circ} \mathrm{C}$. Elemental Analysis $\left[\mathrm{C}_{32} \mathrm{H}_{14} \mathrm{~F}_{34} \mathrm{~N}_{6} \mathrm{O}_{4} \mathrm{Cu}\right]$; Found $\mathrm{C}, 31.20 ; \mathrm{H}, 1.39 ; \mathrm{N}, 6.49 \%$; calculated, C, $30.60 ; \mathrm{H}, 1.12 ; \mathrm{N}, 6.69 \%$; FT-IR (ATR) $\left(\mathrm{mmax} / \mathrm{cm}^{-1}\right) ; 3400(\mathrm{~N}-\mathrm{H}), 1673(\mathrm{O} \bullet \bullet \mathrm{H}-\mathrm{O})(\mathrm{w})$, $1597(\mathrm{C}=\mathrm{N}), 1304(\mathrm{~N}-\mathrm{O}), 1197-1140(\mathrm{C}-\mathrm{F}), 968(\mathrm{~N}-\mathrm{O})$. The green complex was soluble in some organic solvents like THF, DMSO, ethanol and acetone; and insoluble in chloroform, n-hexane and water.

Synthesis of bis(phenanthrenequinone dioxime)copper(II) [Cu(PTQD)2]: Synthesis was done by following the same procedure as described above for [Cu(PTQD)2]. Yield: $98 \%$ m.p.>330 ${ }^{\circ} \mathrm{C}$. Elemental Analysis $\left[\mathrm{C}_{28} \mathrm{H}_{18} \mathrm{O}_{4} \mathrm{~N}_{4} \mathrm{Cu}\right]$; Found $\mathrm{C}, 61.57 ; \mathrm{H}, 3.29 ; \mathrm{N}, 10.03 \%$; calculated, C, 62.51; H, 3.37; N, 10.41\%; IR(ATR) $\left(\mathrm{mmax} / \mathrm{cm}^{-1}\right) ; 3063(\mathrm{C}-\mathrm{H}(\mathrm{ar})), 1594(\mathrm{C}=\mathrm{N})$, 
$1525(\mathrm{C}=\mathrm{C}), 1240-1289(\mathrm{~N}-\mathrm{O})$ 1095-957 (N-O). The green complex was soluble in some organic solvents like THF, DMSO, ethanol and acetone and insoluble in chloroform, $\mathrm{n}$-hexane and water.

Synthesis of bis(3-perfluoro-vic-dioxime)palladium(II) [Pd(3PFVD)2]: The Pd complex was synthesized to be used as metaloorganic precursor according to the methodology given in $(24,25)$. A solution of oxime $(2 \mathrm{mmol})$ in $20 \mathrm{~mL}$ of absolute ethanol was put in a solution of palladium(II) chloride $(1 \mathrm{mmol})$ in $10 \mathrm{~mL}$ of absolute ethanol. Sodium acetate $(0.5 \mathrm{~g})$ was added to the solution. Then the mixture was refluxed at $75^{\circ} \mathrm{C}$ for 4.5 hours. It was allowed to cool to room temperature. The mixture was filtered and dried in a vacuum desiccator to furnish the pure Pd oxime complex. Yield: $70.0 \%$ m.p.: $258{ }^{\circ} \mathrm{C}$. Elemental Analysis $\left[\mathrm{C}_{32} \mathrm{H}_{14} \mathrm{~F}_{34} \mathrm{~N}_{6} \mathrm{O}_{4} \mathrm{Pd}\right.$ ]; Found C, 29.19; H, 1.05; N, 6.12\%; calculated, C, 29.59; H, $1.09 ; \mathrm{N}, 6.47 \%$; FT-IR(ATR) (mmax/cm $\left.{ }^{-1}\right)$; $3302(\mathrm{~N}-\mathrm{H}), 3058(\mathrm{C}-\mathrm{H}(\mathrm{ar})), 1667(\mathrm{O} \bullet \bullet \mathrm{H}-\mathrm{O})(\mathrm{w}), 1617(\mathrm{C}=\mathrm{N}), 1568(\mathrm{C}=\mathrm{C}), 1131(\mathrm{~N}-\mathrm{O}), 1194-$ $1144(\mathrm{C}-\mathrm{F}), 958(\mathrm{~N}-\mathrm{O})$; ${ }^{1} \mathrm{H}$ NMR (DMSO-d $) \delta \mathrm{ppm}: 3.8(\mathrm{~s}, 2 \mathrm{H}, \mathrm{H}-\mathrm{C}=\mathrm{NOH}), 8.0(\mathrm{~s}, 2 \mathrm{H}, \mathrm{Ph}-\mathrm{N}-\mathrm{H})$, 6.8-7.5 ( $\mathrm{m}, 8 \mathrm{H}, \mathrm{Ar}-\mathrm{H})$. The yellowish-orange complex was soluble in some organic solvents like THF, DMSO, ethanol and acetone and insoluble in chloroform, n-hexane and water.

Synthesis of bis(phenanthrenequinone dioxime)palladium(II) [Pd(PTQD)2]: Synthesis was done by following the same method as described above for [Pd(PTQD)2]. Yield: \%90. m.p.>330 ${ }^{\circ} \mathrm{C}$. Elemental Analysis $\left[\mathrm{C}_{28} \mathrm{H}_{18} \mathrm{O}_{4} \mathrm{~N}_{4} \mathrm{Pd}\right]$; Found $\mathrm{C}, 56.19 ; \mathrm{H}, 2.73 ; \mathrm{N}, 7.77 \%$; calculated, C, 57.89; H, 3.12; N, 9.65\%; FT-IR(ATR) (mmax/cm-1); 3065 (C-H(ar)), 1595 $(\mathrm{C}=\mathrm{N}), 1510(\mathrm{C}=\mathrm{C}), 1256-1293(\mathrm{~N}-\mathrm{O}), 1010(\mathrm{~N}-\mathrm{O})$. The yellow complex was soluble in some organic solvents like THF, DMSO, ethanol, and acetone and insoluble in chloroform, n-hexane and water.

Determination of Solubility in Supercritical Carbon Dioxide: The solubility of the precursors was measured in a stainless steel reactor with an inner volume of $54 \mathrm{~mL}$ and equipped with two sapphire windows. In a typical experiment held in $\mathrm{SCCO}_{2}$, the reactor was cleaned with $\mathrm{CO}_{2}$ and ethanol at a pressure of $4.8 \mathrm{MPa}$. A determined amount (45-50 mg) of precursor were weighed and placed inside the reactor. The solubility tests were performed three times at a temperature of $363 \mathrm{~K}$ and pressure $(13.8,20.7$ and $27.6 \mathrm{MPa}$ ) for 4 hours by stirring. At the end of this time, the solubility of each complex in $\mathrm{scCO}_{2}$ was determined quantitatively by releasing $\mathrm{CO}_{2}$ gas from the reactor into a receptacle with an inner volume of $5 \mathrm{~mL}$. The $\mathrm{CO}_{2}$ gas in the receptacle was run through $5 \mathrm{~mL}$ ethanol. The receptacle was washed with approximately $15 \mathrm{~mL}$ ethanol and added to first solution. The standard solutions of complexes among $10^{-7}-10^{-3} \mathrm{M}$ were prepared. These solutions were measured by UV-Vis spectrophotometer at the wavelength of maximum absorption and concentration-absorption graph was drawn according to these data. Molar absorption coefficients were calculated from this graph. The ethanolic solutions of dissolved complexes in $\mathrm{SCCO}_{2}$ were measured at the wavelength of maximum absorption. The amount of precursors dissolved in $\mathrm{scCO}_{2}$ was calculated from Beer law. 
Deposition of Precursors on MWCNT: A stainless steel reactor with a $100 \mathrm{~mL}$ inner volume was used for the deposition of the metals onto MWCNTs. The precursor was first adsorbed onto a MWCNT and then converted to metal nanoparticles (Figure 3). The reactor was firstly cleaned using chemical solvents and then with flowing $\mathrm{CO}_{2}$ under a pressure of $5 \mathrm{MPa}$. $50 \mathrm{mg}$ precursor and $50 \mathrm{mg}$ MWCNT (precursor/MWCNT:1/1 mass ratio) were placed in the reactor. The reactor was heated to $363 \mathrm{~K}$ and charged to $0.69 \mathrm{MPa}$ with $\mathrm{H}_{2}$ gas and to $27.6 \mathrm{MPa}$ with $\mathrm{CO}_{2}$. It was stirred for 4 hours and then the reactor was allowed to cool to room temperature. Then the pressure in the reactor was released. The MWCNTs were then washed by centrifuging with THF until the impurity had been removed. The M/MWCNT nanoparticles were dried in an oven at 75 ${ }^{\circ} \mathrm{C}$. XRD was used to confirm the presence of the metal, the size of its particles. SEM-EDX was used to confirm of the distribution of the metals on the MWCNT and the percent of metals present. HR-TEM was used to confirm of the metals' distribution on the MWCNT and the particle size range.

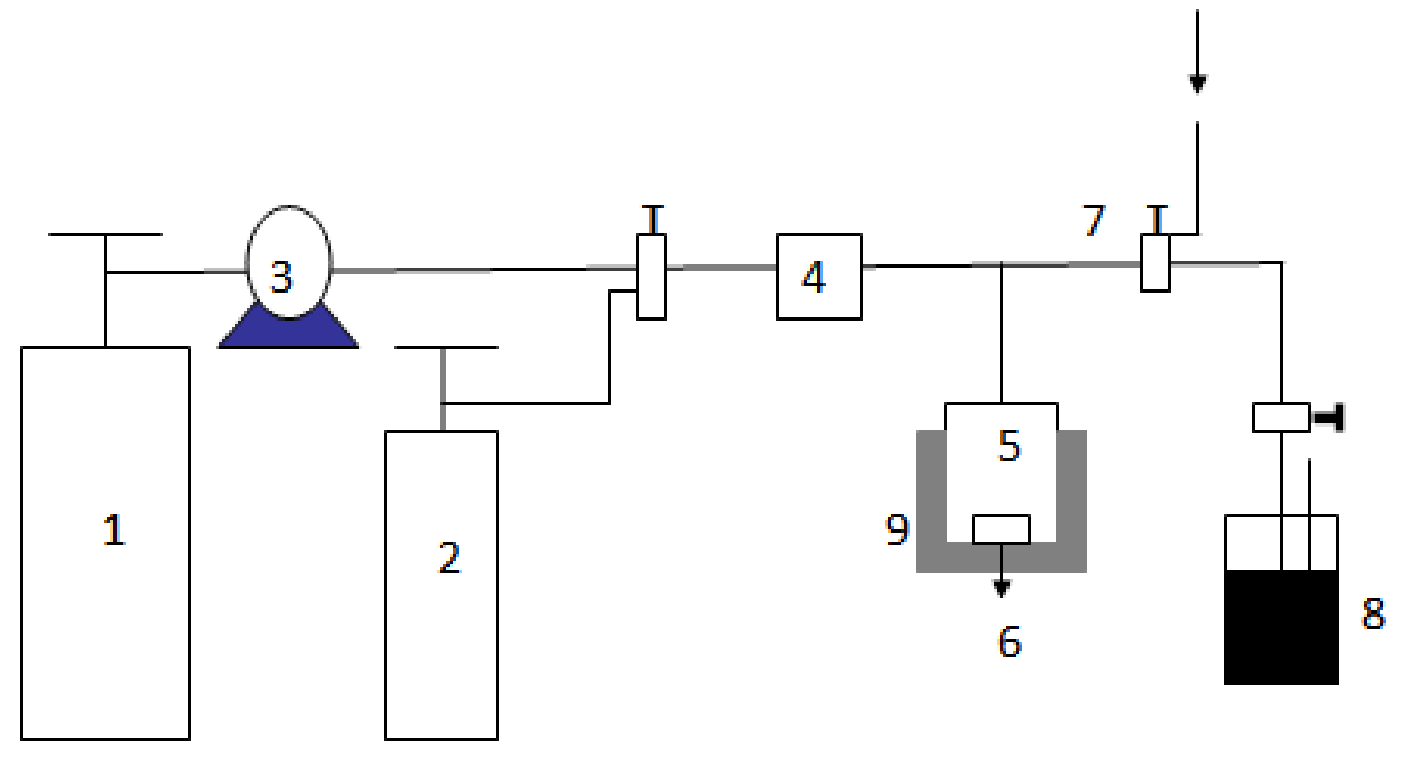

Figure 3. Schematic diagram of deposition system $\left(1: \mathrm{CO}_{2}, 2: \mathrm{H}_{2}, 3\right.$ : Syringe pump, 5 : High pressure reactor, 6: Support and precursor 7: Vent, 8: Receiving vessel, 9: Mantle heater. 


\section{RESULTS AND DISCUSSION}

\section{Structure characterization of ligands and metal complexes (precursors)}

3-Perfluoro vic-dioxime [3PFVD]: The elemental analysis of the [3PFVD] agreed with the calculated values, confirming the successful synthesis of the desired compounds. The FTIR spectra showed characteristic peaks at $3383 \mathrm{~cm}^{-1}(\mathrm{~N}-\mathrm{H}), 3244-3000 \mathrm{~cm}^{-1}(\mathrm{O}-\mathrm{H}), 1680 \mathrm{~cm}^{-1}$ $(\mathrm{C}=\mathrm{N}), 1310 \mathrm{~cm}^{-1}(\mathrm{~N}-\mathrm{O}), 1202 \mathrm{~cm}^{-1}(\mathrm{C}-\mathrm{F})$ and $950 \mathrm{~cm}^{-1}(\mathrm{~N}-\mathrm{O})$. New bands, which were not present in the starting material, appeared between $1100 \mathrm{~cm}^{-1}$ and $1250 \mathrm{~cm}^{-1}$ in the FTIR spectra of 3PFVD which correspond to the new C-F bond. The presence of these as well as the peaks corresponding to $\mathrm{O}-\mathrm{H}, \mathrm{C}=\mathrm{N}$ and $\mathrm{N}-\mathrm{O}$ bonds confirm that the desired ligand was synthesized. The ${ }^{1} \mathrm{H}$ NMR spectra showed two overlapping singlet peaks at $11.5 \mathrm{ppm}$ (19). This is due the presence of two different $=\mathrm{N}-\mathrm{OH}$ groups in the ligand. The rest of the peaks observed in the ${ }^{1} \mathrm{H}$ NMR and ${ }^{19} \mathrm{~F}$ NMR spectra were consistent with what was expected. The expected number of peaks was present in the ${ }^{19} \mathrm{~F}$ NMR spectrum.

Phenanthrenequinone dioxime [PTQD]: The IR spectra of [PTQD] showed peaks at 3140$3050 \mathrm{~cm}^{-1}(\mathrm{O}-\mathrm{H}), 3029 \mathrm{~cm}^{-1}$ (C-H (aromatic)), $1647 \mathrm{~cm}^{-1}(\mathrm{C}=\mathrm{N}), 1598 \mathrm{~cm}^{-1}(\mathrm{C}=\mathrm{C}), 1297-1341$ $\mathrm{cm}^{-1}(\mathrm{~N}-\mathrm{O}), 910-1021 \mathrm{~cm}^{-1}(\mathrm{~N}-\mathrm{O})$. The presence of the $\mathrm{N}-\mathrm{O}, \mathrm{O}-\mathrm{H}$ and $\mathrm{C}=\mathrm{N}$ bands confirm that the desired ligand was procured. The ${ }^{1} \mathrm{H}$ NMR spectra of [PTQD] demonstrated a very sharp singlet peak at 12.45-12.10 ppm, arising from the two identical =N-OH groups present (19). The other peaks observed in the ${ }^{1} \mathrm{H}$ NMR spectra were as expected. All of the spectral data agree with what would be expected for this ligand, so it was determined that the desired ligand was synthesized.

Bis(3-perfluoro-vic-dioxime)palladium(II) [Pd(3PFVD)2]: The elemental analysis data for this complex was in agreement with the calculated values. The analytical and physical data (elemental analysis, magnetic susceptibility) indicated a metal to ligand ratio of $1: 2$ (26). This showed that reactions of [3PFVD] with $\mathrm{PdCl}_{2}$ yielded complexes with the overall formula $\left[P d(3 P F V D)_{2}\right]$. The FTIR spectra of the palladium complex showed that the peaks assigned to the $\mathrm{v}(\mathrm{C}=\mathrm{N})$ frequency shifted downfield from those the free ligand. This is due to coordination of the metal to the nitrogen atom, which in turn weakened the $\mathrm{C}=\mathrm{N}$ bond. For the [3PFVD] ligand, the $\mathrm{C}=\mathrm{N}$ peak was observed at $1680 \mathrm{~cm}^{-1}$. The same peak was shifted downfield to $1667 \mathrm{~cm}^{-1}$ in $\left[P d(3 P F V D)_{2}\right]$. In the free ligand, bands arising from the $\mathrm{O}-\mathrm{H}$ bond were observed. These were lost after complexation $(27,28)$. The magnetic susceptibility of the Pd(II) complex 3PFVD indicated that the complex is diamagnetic.

Bis(3-perfluoro-vic-dioxime)copper (II) [Cu(3PFVD)2: The elemental analysis of the complex is in agreement with calculated values. The analytical and physical data (FTIR and magnetic susceptibility) indicated a metal to ligand ratio of $1: 2$. This showed that reactions of 
[3PFVD] with $\mathrm{Cu}\left(\mathrm{CH}_{3} \mathrm{COO}\right)_{2} \cdot \mathrm{H}_{2} \mathrm{O}$ yielded complexes with the overall formula [Cu(3PFVD $)_{2}$ ]. The FTIR spectra of the complex showed that the peaks assigned to the $v(C=N)$ frequency shifted downfield from those of the free ligand. This is due to coordination of the metal to the nitrogen atom, which in turn weakened the $C=N$ bond. For the [3PFVD] ligand, the $C=N$ peak was observed at $1680 \mathrm{~cm}^{-1}$. The same peak was shifted downfield to $1673 \mathrm{~cm}^{-1}$ for [Cu(3PFVD)2]. In the free ligand, bands arising from the $\mathrm{O}-\mathrm{H}$ bond were observed. These were lost after complexation. The $\mathrm{Cu}(\mathrm{II})$ complexes are paramagnetic as expected and the magnetic susceptibility value of the copper complex is $1.42 \mu \mathrm{B}$.

Bis(phenanthrenequinonedioxime)palladium(II) [Pd(PTQD)2]: The elemental analysis of the complex is in agreement with calculated values. The analytical and physical data (elemental analysis, magnetic susceptibility) indicated a metal to ligand ratio of $1: 2$. This showed that reactions of [PTQD] with $\mathrm{PdCl}_{2}$ yielded complexes with the overall formula [Pd(PTQD $)_{2}$ ]. The FTIR spectra of the complex showed that the peaks assigned to the $v(C=N)$ frequency shifted downfield from those the free ligand. This is due to coordination of the metal to the nitrogen atom, which in turn weakened the $\mathrm{C}=\mathrm{N}$ bond. For the [3PFVD] ligand, the $\mathrm{C}=\mathrm{N}$ peak was observed at $1680 \mathrm{~cm}^{-1}$. The same peak was shifted downfield to $1595 \mathrm{~cm}^{-1}$ for [Pd(3PFVD)2]. In the free ligand, bands arising from the $\mathrm{O}-\mathrm{H}$ bond were observed. These were lost after complexation. Magnetic susceptibility measurements supplied sufficient data to characterize the geometry of the metal complexes. The magnetic susceptibility of the Pd(II) complex PTQD indicated that the complex is diamagnetic.

Bis(phenanthrenequinone dioxime)copper(II) [Cu(PTQD)2]: The elemental analysis of the complex is in agreement with calculated expectations. The analytical and physical data (FTIR and magnetic susceptibility) indicated a metal to ligand ratio of $1: 2$. This showed that reactions of [3PFVD] with $\mathrm{Cu}\left(\mathrm{CH}_{3} \mathrm{COO}\right)_{2} \cdot \mathrm{H}_{2} \mathrm{O}$ yielded complexes with the overall formula [Cu(3PFVD $)_{2}$ ]. The FTIR spectra of the complex showed that the peaks assigned to the $v(C=N)$ frequency shifted downfield from those the free ligand. This is due to coordination of the metal to the nitrogen atom, which in turn weakened the $\mathrm{C}=\mathrm{N}$ bond. For the [3PFVD] ligand, the $\mathrm{C}=\mathrm{N}$ peak was observed at $1680 \mathrm{~cm}^{-1}$. The same peak was shifted downfield to $1594 \mathrm{~cm}^{-1}$ for [Cu(3PFVD)2]. In the free ligand, bands arising from the $\mathrm{O}-\mathrm{H}$ bond were observed. These were lost after complexation. The $\mathrm{Cu}(\mathrm{II})$ complexes are paramagnetic as expected and the magnetic susceptibility value of the copper complex is $2.12 \mu \mathrm{B}$.

\section{Solubility of Precursors}

The solubility of all four complexes was performed, to indicate the suitability of these oxime complexes for using precursor in $\mathrm{scCO}_{2}$ deposition method. The solubility of all synthesized vicdioxime precursors were in agreement with commonly known precursors reported in literature $(29,30)$. The solubility data are shown in Table 1 . Precursors in comparison, the solubility of Pd 
complexes are better than Cu complexes. Distance between ligand and center atom is the bigger in palladium complexes because of palladium diameter is bigger than copper's. The distance between ligand and center atom is inversely proportional to the shielding of the center palladium atom by the ligands. The solubility of Pd complex of 3PFVD was 6.7 times, PTQD was 2 times better than $\mathrm{Cu}$ complexes.

Table1. The solubility data of precursor in $\mathrm{scCO}_{2}$ at different pressures.

\begin{tabular}{|c|c|c|c|c|c|}
\hline \multicolumn{4}{|c|}{ Solubility (molar fraction) } & \multirow{2}{*}{$\begin{array}{c}\text { molar } \\
\text { absorptivity } \\
\text { coefficient } \\
(\varepsilon)\end{array}$} & \multirow{2}{*}{$\begin{array}{c}\text { Wavelength } \\
(\mathbf{n m})\end{array}$} \\
\hline & 2000 (PSI) & $\begin{array}{l}3000 \\
\text { (PSI) }\end{array}$ & $\begin{array}{l}4000 \\
\text { (PSI) }\end{array}$ & & \\
\hline [Pd(PTQD) $)_{2}$ & $1.59 \times 10^{-3}$ & $1.89 \times 10^{-3}$ & $2.74 \times 10^{-3}$ & 14883 & 235 \\
\hline [Cu(PTQD) 2$]$ & $1.06 \times 10^{-3}$ & $1.64 \times 10^{-3}$ & $2.55 \times 10^{-3}$ & 19407 & 236 \\
\hline [Pd(3PFVD) 2$]$ & $3.26 \times 10^{-3}$ & $5.22 \times 10^{-3}$ & $8.27 \times 10^{-3}$ & 6006 & 234 \\
\hline [Cu(3PFVD) 2$]$ & $1.78 \times 10^{-4}$ & $3.96 \times 10^{-4}$ & $9.12 \times 10^{-4}$ & 9761 & 316 \\
\hline
\end{tabular}

\section{Characterization of MW-CNT supported metal nanoparticles}

The following vic-dioxime metal complexes were used as precursors in the deposition process. The deposition was performed in three steps:

(1) Dissolving of the precursor in supercritical carbon dioxide,

(2) Adsorbing of metal complex on the MWCNTs

(3) Supercritical reduction.

A chemical reduction method utilizing $\mathrm{H}_{2}$ gas was employed to deposit $\mathrm{Cu}(0)$ and $\mathrm{Pd}(0)$ form nanoparticles onto MWCNTs. After this step, precursors were converted to metallic $\mathrm{Cu}$ and Pd. However, $\mathrm{Cu}$ nanoparticles were found to convert to $\mathrm{Cu}(\mathrm{OH})_{2}, \mathrm{CuO}$ and $\mathrm{Cu}_{2} \mathrm{O}$ form by contact with oxygen in air after the synthesis.

\section{HR-TEM results}

High resolution TEM image that was taken from the composite obtained from the $\left[\mathrm{Pd}(\mathrm{PTQD})_{2}\right]$ precursor, after its deposition using a 1:1 ratio of precursor: MWCNT indicates that palladium nanoparticles were distributed homogeneously on the MWCNTs. HR-TEM image is shown in Figure 4. The HR-TEM results indicated a size range between 2-5 nm, which is as good as nanoparticles obtained from available precursors $(6,13,14)$. Aggregate of palladium was not observed on MWCNT. The HR-TEM images of Cu/MWCNT composite obtained from [Cu(3PFVD $)_{2}$ ] precursor is shown in Figure 5. These images indicate that the copper nanoparticles are distributed homogeneously on the MWCNTs and there is no aggregate on the substrate. The HRTEM results indicated a size range between $2-5 \mathrm{~nm}$. 

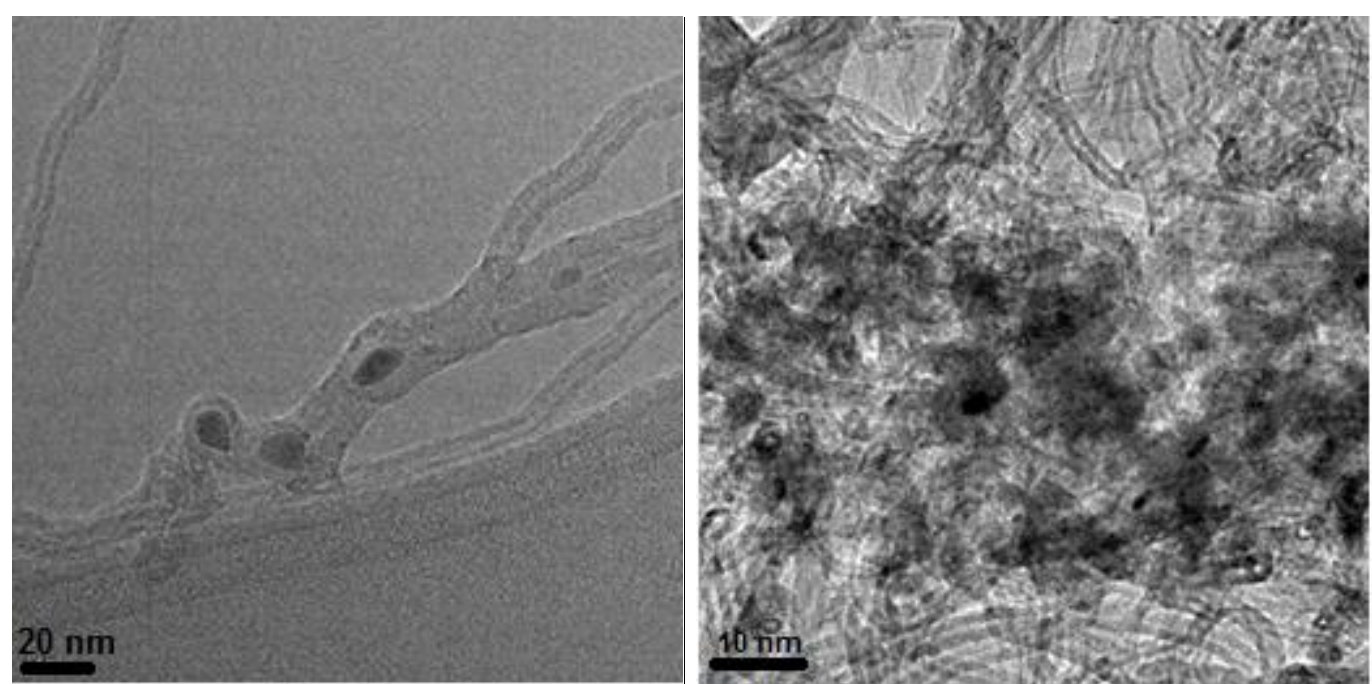

Figure 4. High-resolution TEM images of Pd/MWCNT obtained from [Pd(PTQD)2].
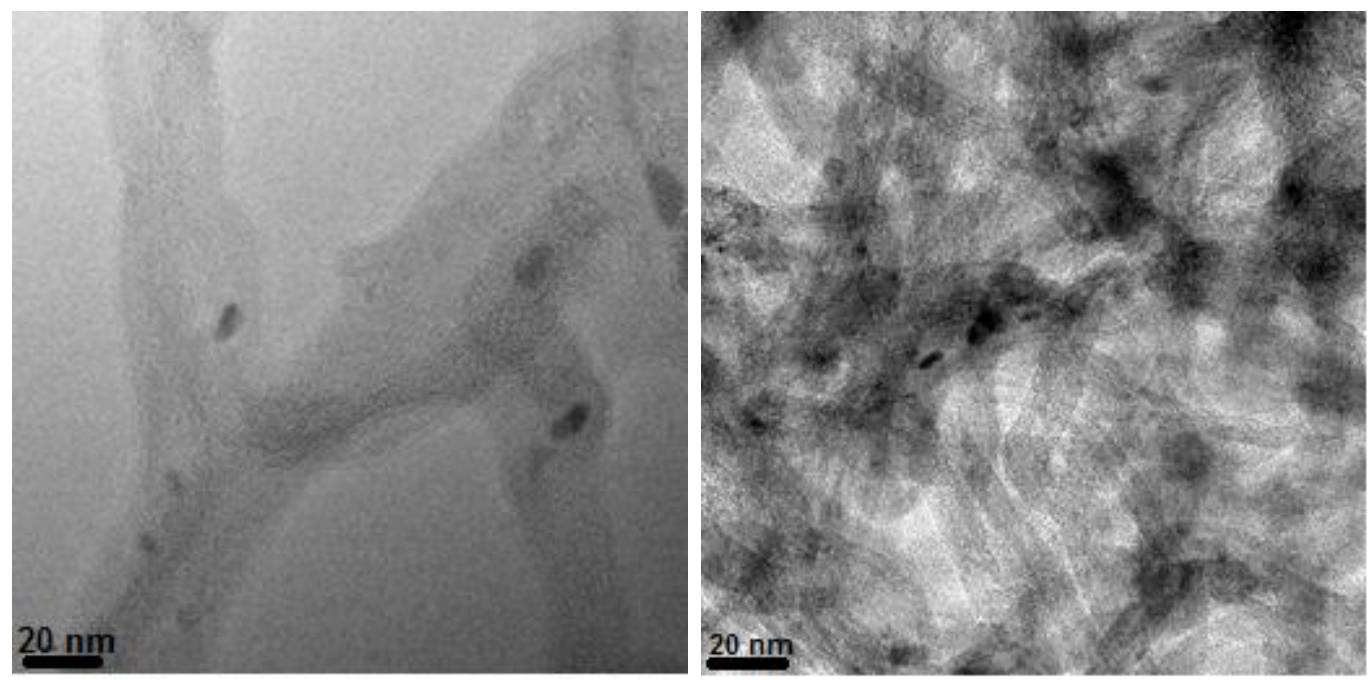

Figure 5. High resolution TEM images of Cu/MWCNT obtained from [Cu(3PFVD)2].

\section{SEM-EDX Results}

The percentages of the metals on the MWCNTs were obtained from SEM-EDX images. SEM-EDX data provided the chemical properties of these particles.

The SEM-EDX micrographs of Pd/MWCNT obtained from [Pd(PTQD) $)_{2}$ is shown in Figure 6(a) and $\left[P d(3 P F V D)_{2}\right]$ is shown in Figure 6(b). These EDX spectra showed that Pd and $C$ atoms are the main elements in these composites. While a high intensity carbon peak was observed, the palladium peak had a relatively low intensity. This is because MWCNTs are the main components in these samples. Metal content was calculated from the EDX data. From the SEM-EDX micrograph of $\mathrm{Pd} / \mathrm{MW}$-CNTs composites indicated that the palladium nanoparticles were distributed homogeneously on the MWCNTS. The ICP-OES and EDX data results showed that the percentage of $\mathrm{Pd}$ on the MWCNTs is $5.6 \% \mathrm{wt}$. (68\% of the total $\mathrm{Pd}$ in the system) for $\left[\mathrm{Pd}(3 \mathrm{PFVD})_{2}\right]$ and $10 \%$ wt. (54.4\% of the total Pd in the system) for [Pd(PTQD) 2 . 


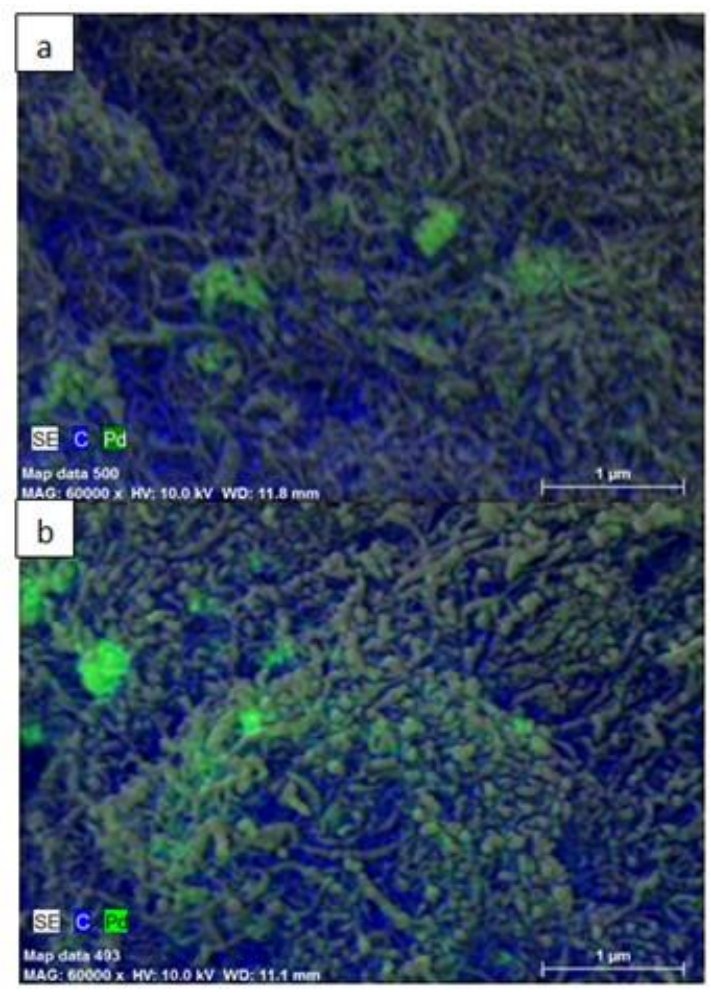

Figure 6. SEM-EDX images of Pd/MWCNT obtained from [Pd(PTQD) 2 (a) and $\left[\operatorname{Pd}(3 P F V D)_{2}\right](b)$.

The SEM-EDX micrographs of Cu/MWCNT obtained from [Cu(PTQD)2] is shown in Figure 7(a) and $\left[\mathrm{Cu}(3 \mathrm{PFVD})_{2}\right]$ is shown in Figure $7(\mathrm{~b})$. The $\mathrm{Cu}$ and $\mathrm{C}$ atoms are the main elements in these composites according to EDX spectra. Carbon peaks were observed to have a high intensity and the copper peaks had relatively low intensity. This is because MWCNTs are the main components in these samples and MWCNT is composed from only carbon atoms (31). EDX figures were used for calculation of metal content. SEM images show that a large fraction of $\mathrm{Cu}$ nanoparticles had very small size. Differently from Pd/MWCNT, there were no $\mathrm{Cu}$ agglomerates on MWCNTs. From the SEM-EDX micrograph of Cu/MWCNTs composites clearly show that the copper is distributed on the MWCNTS. The ICP-OES and EDX data results showed that the percentage of Pd on the MWCNTs is $7.19 \%$ wt. (59.3\% of the total $\mathrm{Cu}$ in the system) for [Cu(3PFVD) 2 ] and $2.3 \%$ wt. (46.5\% of the total $\mathrm{Cu}$ in the system) for [Cu(PTQD) $)_{2}$. 


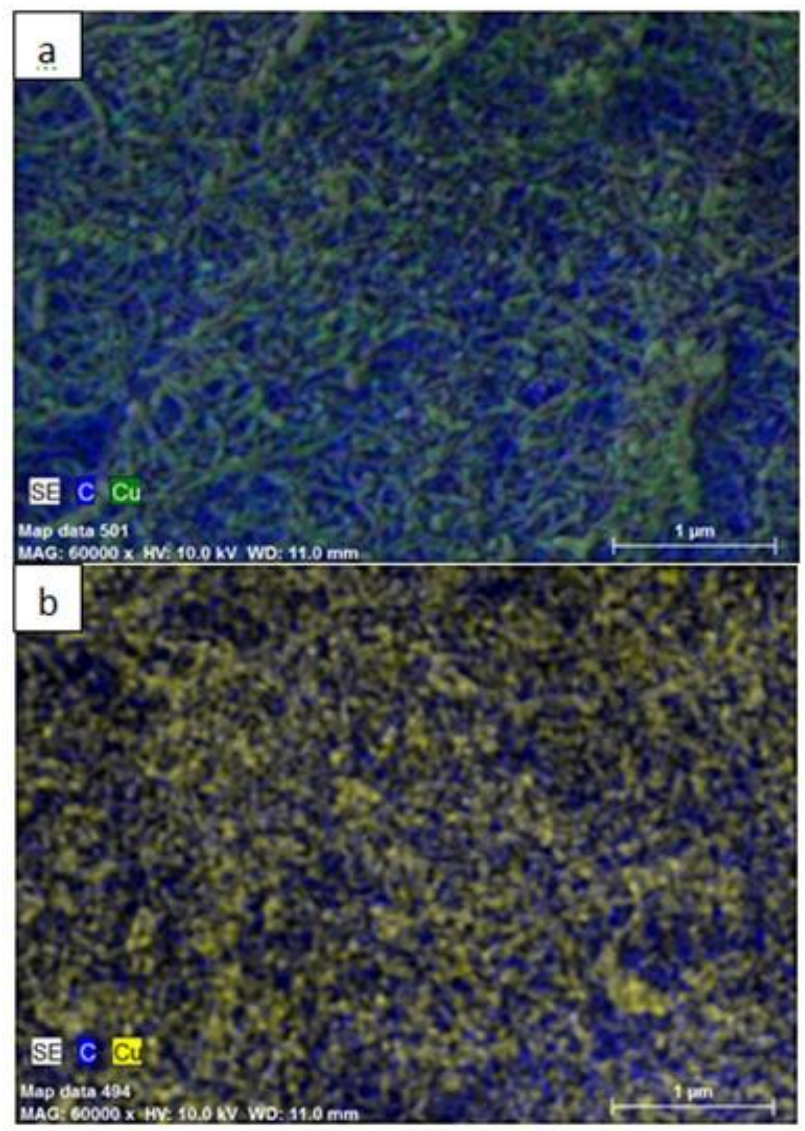

Figure 7. SEM-EDX images of Cu/MWCNT obtained from [Cu (PTQD) $)_{2}$ (a) and [Cu(3PFVD)2] (b).

\section{XRD Results}

The XRD patterns of the Pd/MWCNT composites obtained from the [Pd(PTQD $)_{2}$ ] and $\left[\mathrm{Pd}(3 \mathrm{PFVD})_{2}\right]$ precursors are given in Figure 8 and show that the metals on the MW-CNT surface were polycrystalline. The observed main diffraction peaks of the Pd nanoparticles on the MWCNTs were as expected. Three very sharp diffraction peaks were observed at 40.0, $\mathrm{Pd}(111)$; 46.5, $\mathrm{Pd}(200)$; and 68.1, $\mathrm{Pd}(220)$ (Reference was made to the surface-centered cubic system with JCPDS card number; 46-1043) [7-9, 32]. All these peaks indicate that the Pd metal particles are arranged in a cubic crystallite structure on the MW-CNTs. The average particle size of the Pd metal nanoparticles were calculated according to the Scherrer's equation taking $\operatorname{Pd}(111)$ as the main peak. The mean metal particle size was calculated to be $6.4 \mathrm{~nm}$ for the composite obtained from [Pd(PTQD $)_{2}$ ] and $3.1 \mathrm{~nm}$ for the one obtained from [Pd(3PFVD) 2 ]. The mean particle size obtained from the TEM images was slightly different than that obtained from the XRD data. (Figure 8) 


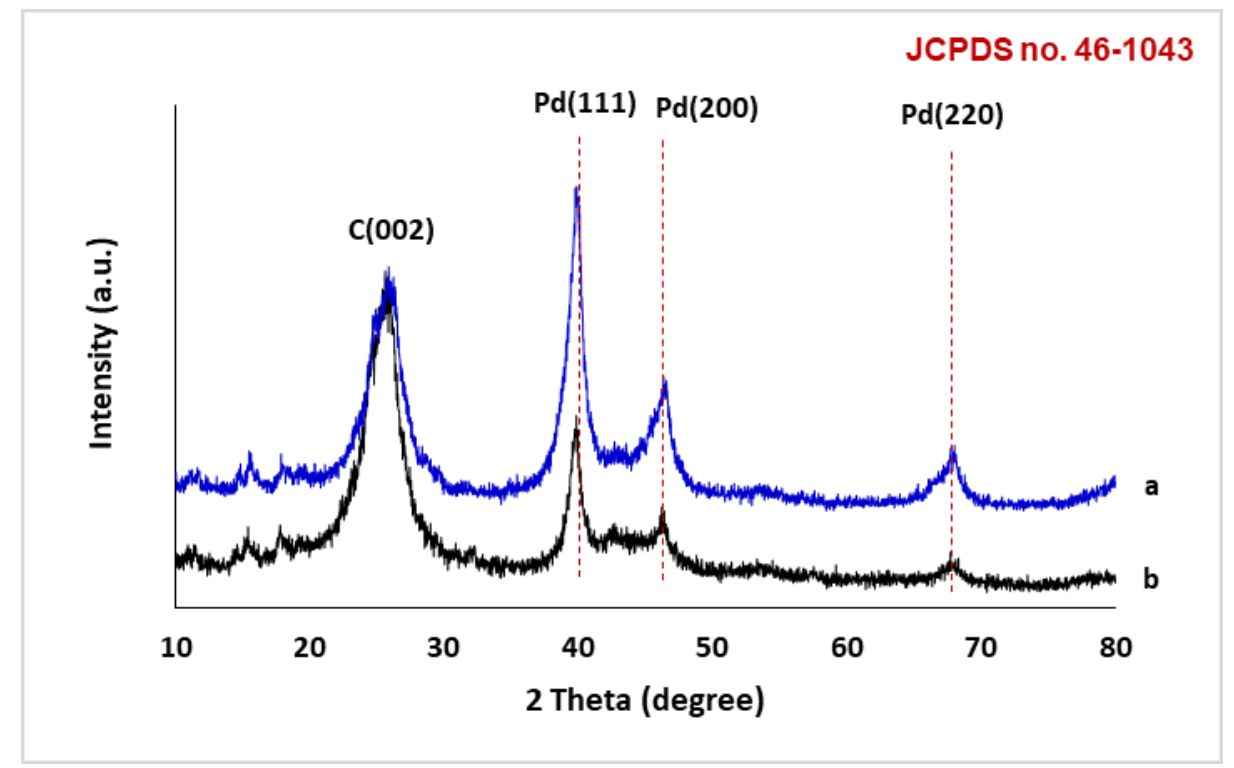

Figure 8. XRD pattern of MWCNT deposited with Pd by [Pd(PTQD) $)_{2}$ (a) and $\left[\mathrm{Pd}(3 \mathrm{PFVD})_{2}\right]$ (b) mechanism of PTQD and it's metal complexes.

The XRD patterns of the Cu/MW-CNT composites obtained from the [Cu(PTQD)2] and $\left[\mathrm{Cu}(3 \mathrm{PFVD})_{2}\right]$ precursors are given in Figure 9 and show that the metals on the MW-CNT surface were polycrystalline. The $\mathrm{Cu}$ nanoparticles seem to have been converted to $\mathrm{CuO}$ and $\mathrm{Cu}_{2} \mathrm{O}$ form by contact with air after removing from the reactor. The observed main diffraction peaks of the $\mathrm{Cu}$ nanoparticles on the MW-CNTs were as expected. Three diffraction peaks were observed at 17.0, $\mathrm{Cu}(\mathrm{OH})_{2}(020)$ (JCPDS 13-420); 33.1, $\mathrm{CuO}(110)$ (JCPDS 48-1548) and 42.3, $\mathrm{Cu}(111)$ (JCPDS 04-0836) (13,21,30-31). The main diffraction peak was observed at 17.0, $\mathrm{Cu}(\mathrm{OH})_{2}$ for [Cu(PTQD) $)_{2}$ and at 33.1, $\mathrm{Cu}(111)$ for [Cu(3PFVD $\left.)_{2}\right] . \mathrm{Cu}$ and $\mathrm{Cu}(\mathrm{OH})_{2}$ peaks for [Cu(3PFVD $)_{2}$ ] and $\mathrm{Cu}$ peak for $\left[\mathrm{Cu}(\mathrm{PTQD})_{2}\right]$ appear to be amorphous. The average particle size of the Cu metal nanoparticles were calculated according to the Scherrer's equation taking $\mathrm{Cu}(\mathrm{OH})_{2}$ for $\left[\mathrm{Cu}(\mathrm{PTQD})_{2}\right]$ and $\mathrm{CuO}$ for $\left[\mathrm{Cu}(3 \mathrm{PFVD})_{2}\right]$ as the main peak. The mean metal particle size was calculated to be $2.0 \mathrm{~nm}$ for obtained from [Cu(PTQD) 2 ] and $2.1 \mathrm{~nm}$ for obtained from $\left[\mathrm{Cu}(3 \mathrm{PFVD})_{2}\right]$. The mean particle size obtained from the TEM images was slightly different than that obtained from the XRD data (Fig.9). 


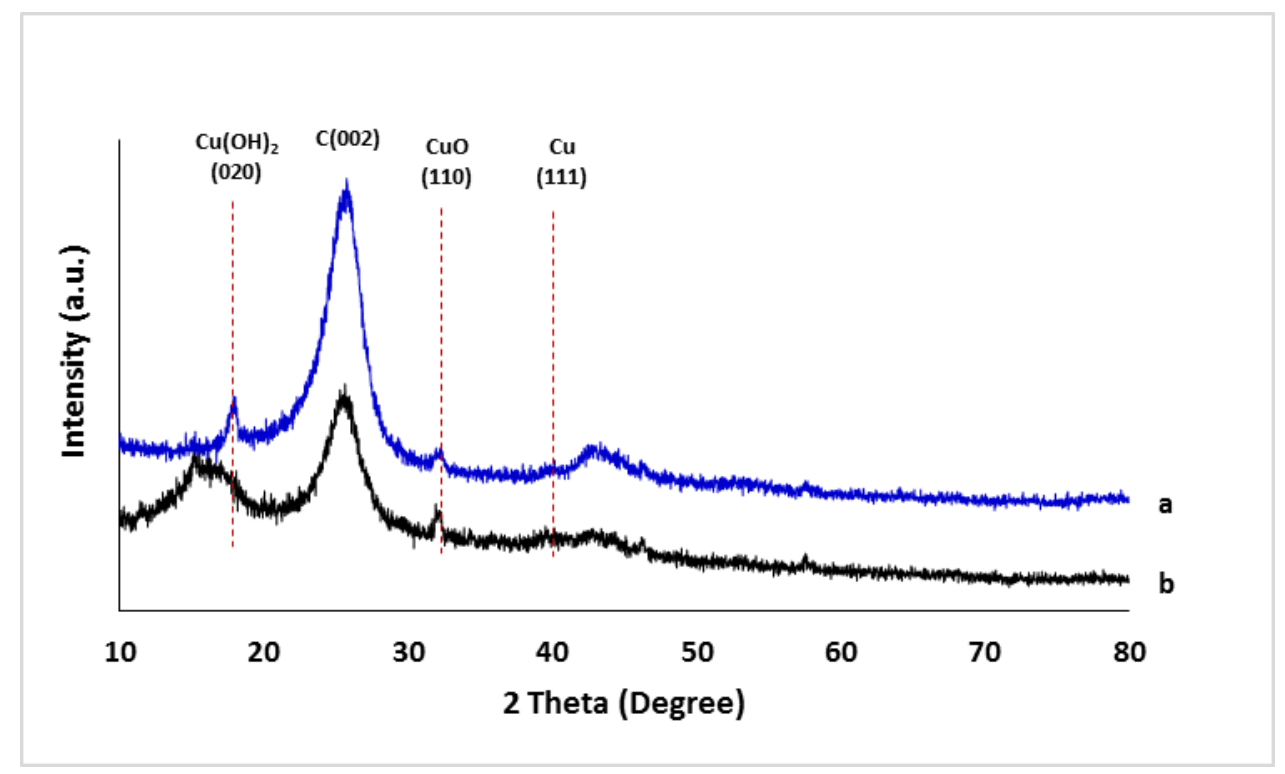

Figure 9. XRD pattern of MWCNT deposited with Pd by [Cu(PTQD) 2 (a) and $\left[\mathrm{Cu}(3 \mathrm{PFVD})_{2}\right](\mathrm{b})$.

\section{CONCLUSION}

Vic-dioxime metal complexes were synthesized, characterized, and used as precursors for the deposition of Pd and Cu nanoparticles on MWCNTs. The resulting composites were analyzed by TEM, SEM-EDX, and XRD. The metal nanoparticles formed were evenly dispersed over the substrate with particle sizes as small as $2 \mathrm{~nm}$. These results clearly show that vic-dioxime metal precursors have been used as a precursor on SCF deposition technique. Further research on the different isomers of vic-dioximes, such as the syn form, could provide insight. This research is hoped to be expanded by studying the deposition of other oxime derivatives on various supports as well as testing the effects of different temperature and pressures during the deposition process.

\section{ACKNOWLEDGMENTS}

The authors acknowledge Prof. Dr. Ramazan Esen from Ç.U. Physics Department for XRD measurements. This study was supported by Scientific and Technological Research Council of Turkey (TUBITAK project number 111T153). These are gratefully acknowledged.

\section{REFERENCES}

1. Ulusal H, Fındıkkıran G, Demirkol O, Akbaşlar D, Giray ES. Supercritical diethylether: A novel solvent for the synthesis of aryl-3,4,5,6,7,9-hexahydroxanthene-1,8-diones. The Journal of Supercritical Fluids. $2015 ; 105 ; 146-50$.

2. Ulusal F, Darendeli B, Erünal E, Eğitmen A, Güzel B. Supercritical carbondioxide deposition of YAlumina supported Pd nanocatalysts with new precursors and using on Suzuki-Miyaura coupling reactions. The Journal of Supercritical Fluids. 2017;127;111-20. 
3. Daoush WM, Lim BK, Mo CB, Nam DH, Hong SH. Electrical and mechanical properties of carbon nanotube reinforced copper nanocomposites fabricated by electroless deposition process. Materials Science and Engineering: A. 2009;513-514;247-53.

4. Park PW, Ledford JS. The influence of surface structure on the catalytic activity of alumina supported copper oxide catalysts. Oxidation of carbon monoxide and methane. Applied Catalysis B: Environmental. $1998 ; 15 ; 221-31$.

5. Rather S, Zacharia R, Hwang SW, Naik M, Nahm KS. Hydrogen uptake of palladium-embedded MWCNTs produced by impregnation and condensed phase reduction method. Chemical Physics Letters. 2007;441;261-7.

6. Cangul B, Zhang LC, Aindow M, Erkey C. Preparation of carbon black supported Pd, Pt and Pd-Pt nanoparticles using supercritical CO2 deposition. The Journal of Supercritical Fluids. 2009; 50; 82-90.

7. Parker HL, Rylott EL, Hunt AJ, Dodson JR, Taylor AF, Bruce NC, Clark JH. Supported Palladium Nanoparticles Synthesized by Living Plants as a Catalyst for Suzuki-Miyaura Reactions. Plos one. 2014; 9; $1-6$.

8. Du H, Li B, Kang F, Fu R, Zeng Y. Carbon aerogel supported Pt-Ru catalysts for using as the anode of direct methanol fuel cells. Carbon. 2007; 45; 429-35.

9. Zhang Y, Erkey C. Preparation of supported metallic nanoparticles using supercritical fluids: A review. The Journal of Supercritical Fluids. $2006 ; 38 ; 252-67$.

10. Dobrovolna Z, Kacer P, Cerveny L. Competitive hydrogenation in alkene-alkyne-diene systems with palladium and platinum catalysts. Journal of Molecular Catalysis A: Chemical. 1998;130;279-84.

11. Ye XR, Lin Y, Whang C, Engelhard MH, Wang Y, Wai CM. Supercritical fluid synthesis and characterization of catalytic metal nanoparticles on carbon nanotubes. Journal of Materials Chemistry. $2004 ; 14 ; 908-13$.

12. Lin $Y$, Cui X, Ye X. Electrocatalytic reactivity for oxygen reduction of palladium-modified carbon nanotubes synthesized in supercritical fluid. Electrochemistry Communications. 2005;7;267-74.

13. Cabanas A, Blackburn J, Watkins J. Deposition of Cu films from supercritical fluids using $\mathrm{Cu}(\mathrm{I}) \beta$ diketonate precursors. Microelectronic Engineering. 2002;64;53-61.

14. Erkey C. Preparation of metallic supported nanoparticles and films using supercritical fluid deposition. The Journal of Supercritical Fluids. 2009;3;517-22.

15. Teoh WH, Mammucari R, Foster NR. Solubility of organometallic complexes in supercritical carbon dioxide: A review. Journal of Organometallic Chemistry. 2013;724;102-16.

16. Guzel B, Avşar G, Çınkır H. Supercritical Carbon Dioxide-Soluble Fluorus vic-Dioxime Ligands and their NiII Complexes: Synthesis, Characterization and Solubility Properties. Synthesis and Reactivity in Inorganic, Metal-Organic, and Nano-Metal Chemistry. 2007;37;801-4.

17. Smart NG, Carleson T, Kast T, Clifford AA, Burford MD, Wai CM. Solubility of chelating agents and metal-containing compounds in supercritical fluid carbon dioxide. Talanta. 1997; 44; 137-50.

18. Peng Q, Hojo D, Park KJ, Parsons GN. Low temperature metal oxide film deposition and reaction kinetics in supercritical carbon dioxide. Thin Solid Films. 2008;516;4997-5003.

19. Yildirim B, Özcan E, Deveci P. New glyoxime derivatives and their transition metal complexes. Russian Journal of Coordination Chemistry. 2007;33;417-21.

20. Ulusal F, Güzel B. Deposition of palladium by the hydrogen assisted on SBA-15 with a new precursor using supercritical carbon dioxide. The Journal of Supercritical Fluids. 2018; 133; 233-8.

21. Chandima A, Arthur DB. Efficient Synthesis of 1,4,5,12-Tetraazatriphenylene and Derivatives. Journal of American Chemical Society. 2004;69;7741-4.

22. Lam F, Hu X. A new system design for the preparation of copper/activated carbon catalyst by metalorganic chemical vapor deposition method. Chemical Engineering Science. 2003;58;687 - 95. 
23. Dervishi E, Li Z, Shyaka J, Watanabe F, Biswas A, Umwungeri JL, Courte A, Biris AB, Kebdani O, Biris AS. The role of hydrocarbon concentration on the synthesis of large area few to multi-layer graphene structures. Chemical Physics Letters. 2011;501;390-5.

24. Yüksel F, Gümüş G, Gürol İ, Ahsen V, Chumakov Y, Jeanneaub E, Luneau D. Channel architecture via self assembly of oxamide oximes complexes. Dalton Transactions. 2008;0; 241-52.

25. Gürol İ, Ahsen V, Bekaroğlu Ö. Synthesis of soluble complexes from a tetradentate dithioglyoxime ligand. Journal of the Chemical Society, Dalton Transactions. 1992; 0; 2283-6.

26. Singh MS, Singh AK. Heterocyclization of vicinal dioximes to seven membered N, P and O heterocycles. Indian Journal of Chemistry -B. 2000; 32; 551-3.

27. Burakevi JV, Lore AM, Volpp GP. Phenylglyoxime. Separation, characterization, and structure of three isomers. The Journal of Organic Chemistry. $1971 ; 36 ; 1-4$.

28. Özcan E, Karapınar E, Demirtas B. Synthesis of four new vic-dioximes and their nickel(II), cobalt(II), copper(II) and cadmium(II) complexes. Transition Metal Chemistry. 2002; 27; 557-61.

29. Rajkumar K, Aravindan S. Tribological studies on microwave sintered copper-carbon nanotube composites. Wear. 2011;270;613-21.

30. Wu HX, Zhang CX, Jin L, Yang H, Yang SP. Preparation and magnetic properties of cobalt nanoparticles with dendrimers as templates. Materials Chemistry and Physics. 2010;121;342-8.

31. Brintzinger $\mathrm{H}$, Titzmann R. Notiz über einige halogenierte aliphatische Oxime. Chemische Berichte.1952;85;344-5.

32. Erünal E, Ulusal F, Aslan MY, Güzel B, Üner D. Enhancement of hydrogen storage capacity of multiwalled carbon nanotubes with palladium doping prepared through supercritical CO2 deposition method. International Journal of Hydrogen Energy. 2017; https://doi.org/10.1016/j.ijhydene.2017.12.058, in press. 
